\title{
Have We Made Progress? Stakeholder Perceptions of Technology Education in Public Secondary Education in the United States
}

\author{
Michael D. Wright, Barton A. Washer, Larae Watkins, and Donald G. Scott
}

Technology education (TE) professionals have debated the role and purpose of technology education and its predecessors in public education for more than a half century (Akmal, Oaks, \& Barker, 2002; Erekson \& Shumway, 2006; Sanders, 2001), or perhaps, since its inception. In addition, these professionals have struggled with the "image" and perceptionthat key stakeholders have of the field (Wicklein \& Hill, 1996; Benson, 1993; Daugherty \& Wicklein, 1993). Many developments have occurred during the past two decades to help clarify these issues such asthe name change from the American Industrial Arts Association to the International Technology Education Association (ITEA) (Streichler, 1985), the Conceptual Framework for the Study of Technology (Savage \& Sterry, 1990), the establishment of the Center for the Advancement of Teaching Technology and Science (CATTS) in 1998 as the professional development arm of the International Technology Education Association (ITEA, 2008), the Rationale and Structure for the Study of Technology (1996), the Standards for Technological Literacy: Content for the Study of Technology (ITEA, 2000), Technically Speaking (Pearson \& Young, 2002), and related Standards Addendums (ITEA, 2002)].

The origins of TE have roots traceable to $18^{\text {th }}$ and $19^{\text {th }}$ century influences, specifically the Enlightenment period in European cultures. However, within the United States, these origins are closely tied to economic interests and influences. Industrialists were a powerful influence in moving higher education and, in turn, public education, toward the practical arts. Yet, it was the ideals ofJohn Dewey and their influence on practical application to theoretical studies that pushed this

Michael D. Wright (mwright@ucmo.edu) is Professor and Dean of the College of Education. Barton A. Washer (bwasher@ucmo.edu) is Associate Professor and Graduate Coordinator in the Department of Career and Technology Education. Larae Watkins (lwatkins@ucmo.edu) and Donald G. Scott (dscott@ucmo.edu) are Coordinators, Research and Curriculum, in the Missouri Center for Career Education. All are affiliated with the University of Central Missouri, Warrensburg. 
practice even further. Thus, Dewey is credited with being the catalyst that triggered much of the growth of technical disciplines in modern American education. By 1913 "the ideal of education for citizenship was virtually inseparable, in practice, from education for practical occupations in the service of industrial needs" (Chafy, 1997, p. 16). This would suggest that much of the origins of TE were tied to the practical needs of industry or job-relevant training.

Differing perspectives regarding of the role and purpose of TE in public education within the United States continue to be widely debated and publicized. Not only has the problem been exacerbated by disgreement and confusion within the TE profession, but also by differing perceptionsoutside the field. In their study of exemplary TE teachers and their associated secondary faculty in math and science, Daugherty and Wicklein (1993) foundthat math and science teachers did not perceive "the study of the development of technology, biological systems, and transportation as being characteristic of technology education" (p. 41). Furthermore, Daugherty and Wicklein found a significant difference between the perceptions held by math and science teachers when compared to exemplary TE teachers. "While there are many examples of successful technology education programs that are grounded in the separate subject approach" (Erekson \& Shumway, 2006, p. 27), a great deal of time and effort continues to be committed to reducing the perceivedidentity crisis of the TE profession.

During the past two decades, many leaders in the TE profession, particularly those in the ITEA, have made concerted efforts to align the field withthe math and science communities, and most recently, with pre-engineering education. Additionally, how strongly standards-based reform movements are affecting the perception of TE are not clear. Therefore, one of the key questions driving this study was to determine the extent to which these developments have influenced the perceptions of TE stakeholders.

According to Wicklein and Hill (1996), the identity crisis, or perceptions thereof, includes both internal and external ignorance about the field, which $\dot{\mathbf{s}}$ being exacerbated by a resistance to change among TE professionals. Prior to the release of the STL (ITEA, 2000), Wicklein and Hill observed:

Technology education professionals should also give attention to clarification of academic content and identity....As content is clarified within the profession, internal questions of identity will be largely alleviated. Once this has happened, issues of identity with external entities can be adequately dealt with... (p. 8).

The publication of Standards for technological literacy: Content for the study of technology (ITEA, 2000) and related addendums have provided a consistent, focused clarification of academic content. Has this contributed to the current misunderstandings of TE as a profession?

According to Akmal et al. (2002), confusion as to the philosophical orientation of TE still exists. One enduring perspective positsthat TE is, or should be, more closely aligned with Career and Technical Elucation (CTE), particularly the Trade and Industrial (T\&I) area. Additionally, many believe TE 
and T\&I share a similar content base. This point was made clear in Rogers (1995) survey of secondary T\&I instructors' perceptions of the TE curriculum. These instructors indicated a significant preference "for the more traditional competencies, such as identification of common hand tools and knowledge of basic materials and processes over more contemporary competencies, such as knowledge of future technologies, the invention process, and hightech applications" (p. 71).

Technology education has also been championed as a K-12 general education program. Many TE professionals have long advocated the social purposes of TE, and its predecessor, industrial arts as being equal to, or perhaps more important than skill development. In this light, Chafy (1997) issued a challenge to TE professionals to move away from skill development toward general education:

Technology education must seek to go beyond the transmission of the most effective and economic usage of "tools" in modern society to include critical investigations of the social purpose of technology. This means embracing a critical approach to technological issues, considering so-called humanistic and social science perspectives on the role of technology in society, and empowering all students to engage in a critical dialog around technology, progress, education, and the meaning of civilizational advancement. (p. 17-18)

In contrast, it would appear the social purposes of TE were apparently not considered by the T\&I teachers in Rogers' (1995) study.

Design and engineering themes have started to emerge as the primary purpose(s) of technology education. Similarities exist in that both themes view technology as designing creative solutions to help humans adapt to their environment. "...As such, technology should be studied and experienced by all as part of general education" (Raizen, Sellwood, Todd, \& Vickers, 1995, p. 11). Indeed, fifteen years ago Benson (1993) suggested the TE field organize and align itself with engineering disciplines. More recently, the ITEA adopted a tagline of "Technology, Innovation, Design, and Engineering." Additionally, the ITEA-CATTS consortium has made a concerted effort to market EngineeringByDesign (ITEA, 2008) as their primary product and focus. Thus, there continues to be an increasing interest in focusing on the engineering aspects of TE (Benson, 1993; Roman, 2006; Wicklein, 2006; Wright, 2004).

The literature reviewed for this study indicates the role, purpose, and goals of technology education are not undersbod by all, and vary by internal and external groups. Clearly, the purpose of TE as outlined by Chafy (1997) and Raizen et al. (1995) is consistent with the belief that, as a school subject, TE is part of general education, and not CTE. Yet, others assertthe current preengineering focus of TE places it squarely back in CTE, albeit different than the T\&I perspective described above. As evidenced by the conflicting viewpoints presented, there continues to be confusion and a lack of consensus regarding the purpose of TE. Therefore, one must ask if progress has indeed been made in clarifying the role and purpose of TE among key stakeholders. 


\section{Purpose}

Akmal et al. (2002) and Sanders (2001) acknowledged the 100-year debate on the purpose[s] of technology education and its debatable ties to industrial arts. The debate has been further fueled by the fact most states classify TE as career and technical education. However, some of these states allow Carl D. Perkins federal funding to support TE while others do not. Therefore, the purpose of this research was to determine the perceptions of selected stakeholders with respect to the role and purpose of TE in public secondary education in the United States. Based on this purpose, the following research questions were devłoped to guide the study:

1. What are the perceptions of various education personnel regarding the purpose of TE in public secondary education?

2. How is TE classified by state departments of education?

3. To what extent are Carl D. Perkins federal funds used to spport TE?

4. What are the perceptions of various education personnel regarding whether TE programs and personnel are treated comparably to other school programs and personnel?

\section{Methodology}

\section{Population and Sample}

The population for this study was technology eduction stakeholders including classroom teachers, principals, area career center directors, counselors, state department supervisors, state directors of career and technical education, and university technology teacher educators. Consistent with Patten (2004), to provide the best information possible, the purposive sample for this study consisted of those technology education stakeholders who subscribed to selected electronic listservs related to TE (see Table 1). Based on the volatility of electronic subscriptions resulting in individuals adding or removing their names from listservs at any time, a definitive count of the population could not be determined. While Field (2005) asserted a sample is only representative of its population if drawn randomly, true random sampling was not possible for this study. Thus, broad generalizations of the findings of this research should be made within the context of this sample and the resulting data must be interpreted accordingly.

An invitation to participate in the survey and a link to the survey web site was emailed to selected stakeholders of TE through 11 different listservs (see Table 1). In some cases, the survey invitation was emailed directly by the researcher, and in other cases it was emailed by a member of thatrespective listserv. Four hundred-twenty nine respondents accepted the Human Subjects release form on page one of the survey instrument. The study sample consisted of 381 respondents who answered all of the required demographic fields which allowed them to gain access to the content questions. 
Table 1

Organizational listservs to which the invitation to participate was posted Group/Organization

Council for Technology Teacher Education of the International Technology

Education Association

Idea Garden - International Technology Education Association

Mississippi Valley Technology Teacher Education Conference

Missouri Association of Secondary School Principals

Missouri Council of Career and Technical Administrators

Missouri School Counselors Association

National Association of State Directors of Career \& Technical Education

Project Lead the Way national teachers network

State Supervisors of TE

Technology Education Association of Missouri

Technology Education Division of the Association for Career and Technical

Education

Instrumentation

Due to the relatively large size of the population, an electronic Webbased survey instrument was determined to be the most efficient means of collecting the data. Dillman (2000) suggested Web-based surveys are as effective as traditional paper surveys and can reduce data collection time from weeks to hours. Surveys are also recognized as a primary method of collecting reliable and valid information directly from study participants about their feelings, motivations, and beliefs (Fink \& Kosecoff, 2005). In addition, Web-based methods can reduce the cost of conducting largescale surveys when compared to traditional mailing costs (Dillman, Fink \& Kosecoff).

Another factor in designing the instrument was the desire to ask 6llow-up questions to elicit more specific details when appropriate. Specifically, the researchers wanted to be able to ask additional questions of members of certain groups. A Web-based survey also provided options not available with other types of survey instruments. According to Dillman (2000),

Being able to ask questions with many answer choices in a closed-ended fashion makes it possible to use the answer as a screening question that directs respondents to a unique set of questions about the state in which they live, something that would most likely be impractical for a paper questionnaire. (p. 354)

Upon consideration of all factors, implementing a web-based survey was determined to be the best instrumentation option for this study.

The researcher-developed survey instrument was organized into five content sections with 23 questions as well as a demographic section. In detail the items were distributed as follows: Demographics ( 3 required fields, 3 optional fields); Purpose of TE (6 questions); Classification of TE (2 questions); Use of Carl D. Perkins Federal Funds (2 questions); Technology Educators' Actions to 
Influence Federal Funding (3 questions); and Treatment of TE in Public Secondary Schools (10 questions). Content validity of the survey questions was established through the participation of a select group of TE stakeholders. This eight-member group included technology education classroom teachers, technology education teacher educators, a state supervisor for technology education, a representative of state career and technical education directors, a state director for counselor education, and an independent researcher not affiliated with this research. This group validated the final version of the survey in that it measured what it was intended to measure.

The opening page of the survey outlined potential participants' rights as human subjects. This page required each participant to make a selection (forced) indicating consent prior to being directed to the first page of survey questions. The first page of the survey requested demographic information that consisted of three required fields: (a) state, (b) membership in professional associations, and (c) current employment position. Respondents were required to answer all three fields before being directed to the content portion of the survey.

Several questions had sub-questions that only appeared if a specified response was given to the primary question. For example, if a respondent indicated "Yes" to a question, they may have received another questionor series of questions to provide more detailed information. A respondent who answered "No" to the same question was not presented the sub-questions.

Since the data collected were primarily nominal data, a Chisquare test was determined to be appropriate to determine statistical significance. The findings are presented consistent with the four research questions.

\section{Findings}

The findings of this research are based on 381 respondents who answered all of the required fields, thereby gaining access to the contentquestions. Two hundred six (54\%) of the respondents were from Missouri, 175 (46\%) were from other states. As discussed below, statistical tests indicated no significant difference in responses when disaggregated by state.

\section{Demographics}

The 381 survey completers represented 39 states and one US territory (American Samoa). Eighty percent (80\%) of the respondentswere male, $19 \%$ female, and $1 \%$ did not indicate their gender. Many of these respondents held memberships in multiple professional associations. The distribution of professional memberships is presented in Table 2.

Five associations were specific to Missouri. To determine if the number of additional listservs in Missouri might have had a statespecific influence on the overall data, Missouri and non-Missouri responses were compared. Notably, there were no practical or statistically significant differences between Missouri and Non-Missouri respondents except with respect to the magnitude of the response. These data will be discussed in the appropriate setion. The employment Positions reported by the respondents are presented in Table 3. 
Table 2

Memberships in professional associations $(n=409)$

\begin{tabular}{lrr}
\hline Professional Association & $\boldsymbol{f}$ & \multicolumn{1}{c}{$\%$} \\
\hline Association for Career and Technical Education (ACTE) & 127 & 33.3 \\
Council for Technology Teacher Education (CTTE) & 67 & 17.6 \\
International Technology Education Association (ITEA) & 167 & 43.8 \\
Mississippi Valley Technology Teacher Education & 23 & 6.0 \\
$\quad$ Conference (MVTTEC) & 77 & 20.2 \\
Missouri Association of Career and Technical Education & & \\
$\quad$ (Mo-ACTE) & 79 & 20.7 \\
Missouri Association of Secondary School Principals & & \\
$\quad$ (MASSP) & 45 & 11.8 \\
Missouri Council of Career and Technical Administrators & & \\
$\quad$ (MCTTA) & 6 & 1.6 \\
Missouri School Counselors Association (MSCA) & 71 & 18.6 \\
National Association of Secondary School Principals & & \\
$\quad$ NASSP) & 58 & 15.2 \\
Project Lead the Way® national teachers network (PLTW) & 54 & 14.2 \\
Technology Education Association of Missouri (TEAM) & 29 & 7.6 \\
\hline None & & \\
\hline
\end{tabular}

Note: Multiple responses were allowed

Although initial data analyses were attempted using all 381 respondents, the researchers, in consultation with a statistician, excluded the responses from counselors and state directors of CTE due to insufficient cell size. Therefore, the following findings are based on 363 respondents.

Table 3

Positions held by respondents

\begin{tabular}{lcc}
\hline Position & $\boldsymbol{n}$ & $\mathbf{\%}$ \\
\hline Principal & 87 & 22.8 \\
Teacher educator & 84 & 22.0 \\
High school TE teacher & 82 & 21.5 \\
Middle/junior high school TE teacher & 48 & 12.6 \\
Area CTE school Director & 44 & 11.5 \\
State supervisor for TE & 18 & 4.7 \\
State director of CTE & 12 & 3.1 \\
Counselor & 6 & 1.6 \\
Total & 381 & 100.00 \\
\hline
\end{tabular}

Purpose of Technology Education

Research Question One was addressed by six itemsregarding the respondents' perceptions of the purpose of TE and preengineering programs. The first three items requested the respondents to categorize the purposes of TE in public schools into one of three groups:Historical (what existed in the past), 
In Theory (conceptually what should be), andIn Practice (what currently exists). The fourth question allowed only a single response to indicate what the respondent believed to be the Primary Purpose of TE. The last two questions of this section focused on the purpose of pre-engineering programs (e.g., Project Lead the Way ${ }^{\mathbb{B}}$ [PLTW]).

Table 4

Purpose(s) of technology education ( $n=363)$

\begin{tabular}{|c|c|c|c|c|c|c|}
\hline \multirow[b]{2}{*}{ Type of Program } & \multicolumn{2}{|c|}{ 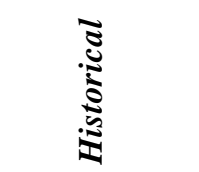 } & \multicolumn{2}{|c|}{ 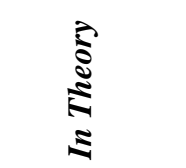 } & \multicolumn{2}{|c|}{ 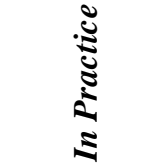 } \\
\hline & $f$ & $\%$ & $\boldsymbol{F}$ & $\%$ & $f$ & $\%$ \\
\hline $\begin{array}{l}\text { Academic program/course of } \\
\text { study }\end{array}$ & 77 & 21.2 & 135 & 37.2 & 113 & 31.1 \\
\hline $\begin{array}{l}\text { Avocational program/course } \\
\text { of study }\end{array}$ & 113 & 31.1 & 64 & 17.6 & 103 & 28.4 \\
\hline CTE program/course of study & 203 & 55.9 & 230 & 63.4 & 219 & 60.3 \\
\hline $\begin{array}{l}\text { Pre-vocational program/course } \\
\text { of study }\end{array}$ & 154 & 42.4 & 133 & 36.6 & 159 & 43.8 \\
\hline $\begin{array}{l}\text { Pre-engineering } \\
\text { program/course of study }\end{array}$ & 33 & 9.1 & 113 & 31.1 & 104 & 28.7 \\
\hline Don't Know & 17 & 4.70 & 10 & 2.8 & 11 & 3.0 \\
\hline
\end{tabular}

Note: Multiple responses were allowed

The dominant response for the Historical, In Theory, and In Practice purposes of TE was "Career \& Technical Education." ForHistorical and In Practice, "Pre-vocational" was the second most frequent response. Table 4 presents a comparison of the responses.

However, when forced to select a singlePrimary purpose of TE "Career \& Technical Education" was selected more than twice as often as the next highest response of "Academic program." A Chi square test indicated statistical significance $(p=.000)$ (see Table 5). This response was consistent among respondents' Position groups as listed in Table 3 . There were no statistically significant differences by position with regard to CTE as the primary purpose of TE. However, there was practical significance in that all groups indicated CTE was the primary purpose of TE.

The researchers further analyzed the data by subdividing the respondents into two groups based on membership in either ACTE or ITEA, but not both. While both groups agreed CTE was the primary purpose of TE (ACTE $=65.3 \%$, ITEA $=40.8 \%$ ), there was a statistically significant difference in the magnitude between the membership groups $(p=.000)$. 
Table 5

Primary purpose of technology education $(n=325)$

\begin{tabular}{lrr} 
Type of Program & $\boldsymbol{f}$ & \multicolumn{1}{c}{$\%$} \\
\hline Academic program/course of study & 62 & 19.1 \\
Avocational (hobby or recreational) program/course of study & 19 & 5.8 \\
Career and Technical Education program/course of study & $* 157$ & 48.3 \\
Pre-vocational program/course of study & 52 & 16.0 \\
Pre-engineering program/course of study & 18 & 5.5 \\
Don't Know & 17 & 5.2 \\
Total & 325 & 100.0 \\
\hline
\end{tabular}

$* p=.000$

Since responses from listservs in Missouri exceeded those outside of the State, Missouri and non-Missouri responses were compared. For Question \#4, the primary purpose of TE, the results were virtually identical.Among nonMissouri residents, $48.4 \%$ indicated that CTE was the primay purpose of TE compared to $48.3 \%$ of Missouri respondents. There were no statistically significant differences between Missouri teachers and all otherrespondents ( $p=$ $.058)$.

Pre-engineering perceptions.

The perceptions stakeholders held with respect to pe-engineering courses and programs (e.g., PLTW ${ }^{\circledR}$ ) was also investigated in light of the current trend to focus on engineering as a main component of TE. Thirtyfive percent $(35 \%)$ of the respondents indicated the primary purpose of pre-engineering programs was "Career \& Technical Education" (see Table 6). Twenty-six percent (26\%) of the respondents indicated "Academic" was the primary purpose of pre-engineering programs, contrasted with 19\% who indicated "Academic" for technology education programs. There were no statistical differences between respondent groups by position (e.g., teacher, principal, teacher educator, etc.).

Table 6

Primary purpose of pre-engineering programs $(n=321)$

\begin{tabular}{lrr}
\hline Type of Program & $\boldsymbol{f}$ & \multicolumn{1}{c}{$\%$} \\
\hline Academic program/course of study & 84 & 26.2 \\
Avocational (hobby or recreational) program/course of study & 5 & 1.6 \\
Career and Technical Education program/course of study & 112 & 34.9 \\
Pre-vocational program/course of study & 33 & 10.3 \\
Don't Know & 87 & 27.1 \\
Total & 321 & 100.0 \\
\hline
\end{tabular}


Classification of Technology Education in StateDepartments of Education

The perception of $55 \%$ of the respondents was that TE as a subject is classified as CTE in their state. Seventeen percent (17\%) indicated TE was classified as Academic, with 17\% indicating they didn't know (see Table 7).

Table 7

Classification of technology education by departments of education $(n=332)$

\begin{tabular}{lrc}
\hline Classification & $\boldsymbol{f}$ & $\mathbf{\%}$ \\
\hline Academic & 57 & 17.2 \\
Avocational & 5 & 1.5 \\
CTE & 184 & 55.4 \\
Pre-vocational & 23 & 6.9 \\
Pre-engineering & 6 & 1.8 \\
Don't know & 57 & 17.2 \\
Total & 332 & $100.0 \%$ \\
\hline
\end{tabular}

Two-thirds of the respondents indicated that TE is administered in CTE units within their State Departments of Education (see Table 8).

Table 8

Administrative location of technology education in doe $(n=332)$

\begin{tabular}{lrr}
\hline Administrative Unit & $\boldsymbol{f}$ & $\mathbf{\%}$ \\
\hline Curriculum \& Instruction & 53 & 16.0 \\
Career \& Technical Education & 223 & 67.2 \\
Don't know & 45 & 13.6 \\
Other & 11 & 3.3 \\
Total & 332 & 100.0 \\
\hline
\end{tabular}

Use of Carl D. Perkins Federal Funds

Seventy percent $(70 \%)$ of the respondents, representing 31 states, indicated it was permissible to use Carl D. Perkins federal funds tosupport TE programs in their state. Of the respondents reporting they were permitted to use Perkins funds, $83 \%$ reported they actually received these funds, representing 29 states. The items for which they are allowed to use federal funds are listed in Tabe 9. The majority of the respondents (76\%) felt that Carl D. Perkins federal funds were critical to maintaining TE as a subject in secondary schools in their state.

Technology educators' actions to influence Carl D. Perkins federal funding.

One hundred eighty-six respondents wrote 208 comments related to what actions technology educators are taking to influence Carl D. Perkins funding for TE. The comments were grouped into seven categories by the researchers. Three individual raters independently reviewed the comments to categorize them. Consensus was reached on $100 \%$ of the comments. Even though $76 \%$ of the respondents indicated Perkins funding was critical to maintaining TE programs 
Table 9

Uses of Carl D. Perkins federal funds

\begin{tabular}{lrr}
\hline Use of Perkins Funds & $\boldsymbol{f}$ & $\mathbf{\%}$ \\
\hline Equipment & 79 & 27.3 \\
Professional Development & 67 & 23.2 \\
Curriculum Development & 62 & 21.4 \\
General Operations & 36 & 12.5 \\
Salaries & 30 & 10.4 \\
Special Incentives & 7 & 2.4 \\
Other & 8 & 2.8 \\
Total & 289 & 100.0 \\
\hline
\end{tabular}

in their state, when queried about what specific actons technology educators were taking in their state to influence Perkins legislation, $43 \%$ indicated either nothing or they were not aware of any actions Lobbying legislators was the next most frequent action being taken, cited by $28 \%$.The specific actions taken by technology educators to influence Carl D. Perkins federal funding to include TE as reported by survey respondents are listed in Table 10 .

Table 10

Actions by technology educators to influence Perkins funding

\begin{tabular}{lrr}
\hline Actions Being Taken & $\boldsymbol{f}$ & \% \\
\hline Nothing - No Actions being taken & 24 & 11.5 \\
I don't know of any actions being taken & 65 & 31.3 \\
Lobbying legislatures/writing/calling & 59 & 28.4 \\
Relying on associations to lobby & 19 & 9.1 \\
Revising programs to become "fundable" under Perkins & 19 & 9.1 \\
Relying on Superiors or State Dept. to lobby & 12 & 5.8 \\
Other & 10 & 4.8 \\
Total & 208 & 100.0 \\
\hline
\end{tabular}

Treatment of TE Programs and Personnel in Public Secondary Schools

The treatment of TE as a subject as well as technology educators, in public secondary schools is a complex issue and highly subjective. Nevertheless, the perception may be as important as reality. It describes the human and physical environment in which TE professionals work on a daily basis. This section of the survey asked respondents to indicate whether they believed TE as a subjet and its teachers were treated comparably tocore academic teachers/subjects and other career \& technical educationteachers/subjects. For those who indicated they believed TE was treated differently, a subset of questions allowed them to indicate how it was treated differently (more or less on several key factors).

The respondents were evenly divided on the question of whether TE teachers are treated comparably to core academic teachers, with $51 \%$ responding Yes and $49 \%$ No. However, there was a statistically significant difference $(p=$ 
$.000)$ in the response of principals compared to all other groups;principals indicated more frequently that they perceived TE teachers were treated comparably to core academic teachers. Overall, less respect/status was perceived to be the primary way in which TE teachers were treated differently than core academic teachers, followed by class time being valued less by administrators (see Table 11).

Eighty-three percent (83\%) of the respondents believed TE teachers were treated comparably to CTE teachers. Once again, there was a statistically significant difference $(p=.022)$ in the response of principals compared to all other groups, with principals indicating more oftenthat they thought TE was treated comparably. The results were the same as for core academic teachers, with respondents indicating TE teachers receivedless respect/status as the primary factor in which TE teachers were treated differently, followed byclass time being valued less by administrators Table 11 lists how respondents who indicated a difference believe TE teachers are treated differently than core academic and CTE teachers.

Table 11

Perceptions of equity of TE teachers' treatment compared to academic and CTE teachers

\begin{tabular}{lccccc}
\hline & \multicolumn{2}{c}{ Academic } & & \multicolumn{2}{c}{ CTE } \\
\cline { 2 - 3 } \cline { 5 - 6 } Topic & $\begin{array}{c}\text { More } \\
\text { \% }\end{array}$ & $\begin{array}{c}\text { Les S } \\
\text { \% }\end{array}$ & & $\begin{array}{c}\text { More } \\
\text { \% }\end{array}$ & $\begin{array}{c}\text { Less } \\
\text { \% }\end{array}$ \\
\hline Inclusion in faculty activities & 12 & 55 & & 4 & 17 \\
$\begin{array}{l}\text { Respect/status/ perception of value } \\
\text { as a professional }\end{array}$ & 6 & 112 & & 3 & 31 \\
$\begin{array}{l}\text { Funding for professional } \\
\text { development }\end{array}$ & 12 & 64 & & 4 & 20 \\
$\begin{array}{l}\text { Assignment of extra duties during } \\
\text { the school day }\end{array}$ & 27 & 25 & & 9 & 8 \\
$\begin{array}{l}\text { Class time valued by administrators } \\
\text { Protection of planning time }\end{array}$ & 4 & 91 & & 3 & 24 \\
Other & 8 & 48 & & 3 & 14 \\
\hline
\end{tabular}

Sixty-seven percent (67\%) of the respondents felt that TE as asubject was not treated comparably to core academic subjects. There was a statistically significant difference in the response of principals compared to high school teachers $(p=.000)$. Seventy-nine percent $(79 \%)$ of the principals indicated TE as a subject was treated comparably to academic subjects, compared to only $18 \%$ of the high school teachers. There was strong agreement that a lack of 
respect/status/program value was the primary way that TE was treated differently than core academic subjects, selected more than twice as often as any other factor by those who indicated TE was not treated comparably.

In contrast, $79 \%$ of the respondents indicated they believed TE as a subject was treated comparably to other CTE programs. Again, there was a statistically significant difference in the response of principals compared to high school teachers $(p=.030)$. While only $79 \%$ of the high school teachers indicated TE as a subject was treated comparably to other CTE subjects, $94 \%$ of the principals indicated it was treated equally.

The survey respondents indicated strongly that theybelieved TE was used as a dumping ground in public secondary education (65.7\%), and even stronger that pre-engineering programs (e.g., Project Lead The Way ${ }^{\circledR}$ ) were not a dumping ground $(87.6 \%)$. There was a statistically significant difference $p=.000$ ) between principals and the other groups, with principals stating that TE was not a dumping ground. There was also a statistically significant difference between middle and high school TE teachers' responses $(p=.047)$, with high school teachers more frequently envisioning TE as a dumping ground. However, there were no significant differences between middle and high school teachers' responses that pre-engineering courses were not a dumping ground $(p=.829)$

Nearly as many respondents indicated that TE wasnot a college prep curriculum $(82.5 \%)$ as indicated that pre-engineering programs were $(76.9 \%)$. Expressed differently, more than four times as many respondents indicated that pre-engineering programs (e.g., PLTW $^{\circledR}$ ) were college preparatory compared to TE programs. Students enrolled in TE were not believed to be primarily college bound, contrasted with pre-engineering programs. There was not a statistically significant difference among groups in this perception.

\section{Summary and Conclusions}

Although respondent demographics may limit the generalizability of the data, the 381 respondents from 39 states and one U.S. Territory represented an interesting perspective on the field of technology education. The selfreport data supported the assertion that TE leadership has strugged for decades to define TE as a "new basic," a core academic subject in the public schools comparable to math and science. To this end, leaders have lobbied to position TE as a general education subject apart from CTE. However; as revealed by the surveyresponse data, lobbying efforts have failed to convince the professionals within the field who participated in this study.

Historically, in theory and in practice, the survey respondents perceived TE to be a CTE program regardless of their employment position. The respondents selected CTE as the "primary" purpose of TE more than twice as oftenas they indicated it to having primarily an academic purpose. Nearly half of the respondents who indicated this also identified themselves as members of ITEA only, and not members of ACTE. This constitutes an apparent contradiction with the stated goals and activities of the ITEA leadership. Preengineering programs were also viewed as CTE, but not to the same magnitude as technology education. This finding is interesing in that the dominant pre-engineering 
program $\left(\mathrm{PLTW}^{\circledR}\right)$ has worked closely with the CTE field and leadership, even embracing CTE as a viable partner and avenue for its delivery. If preengineering is a major component of TE, why do these apparent discrepancies exist?

To illustrate these discrepancies, a majority of the respondents classified TE as CTE in their respective states. This status remains despite more than two decades of intense work to position TE as a general education subject. The data from 29 states also suggested that it was permissible to use Perkins funds for TE programs and identified these funds as critical to maintaining TE programs. Ironically, $43 \%$ were unaware of any proactive actions being taken to ensure TE's continued eligibility in the Perkins program This came as a surprise in that ITEA leadership has actively sought to distance TE from CTE.

Respondents were evenly divided on whether TE teachers were treated comparably to core academic teachers. However, there was a significant difference in the perception of principals, who believed the two groups of teachers were treated comparably. While the respondents indicated TEas a subject was not regarded comparably to core academic subjects, the principals again differed from the rest by indicating that they felt TE was regarded comparably to core academic subjects.

Is there truly a difference in the treatment of TE and principals failed to acknowledge or realize it? While it is possible that principals provided responses that might be "politically correct," one may assume survey results are based on the assumption that respondents, when guaranteed anonymity, will provide honest and truthful responses. Concomitantly, one could arguethat the TE profession is carrying "baggage" - that we may have a lower opinion of ourselves and our self-worth than do others.

TE was also viewed as a dumping ground, a stigma that has long prevailed in CTE. While high school TE teachers supported this view, there was a significant difference in perceptions indicated by middle school TE teachers. Given the nature of the differences between middle and high school programs, this finding was not surprising. Conversely, pre-engineering programs were not perceived as a dumping ground.

The data also suggested that TE was not a college preparatory program and TE students are not, for the most part,college bound. However, pre-engineering programs like $\mathrm{PLTW}^{\circledR}$ were viewed as college preparatory programs four times as often as TE programs. These views were consistent amongthe groups represented, including TE professionals. If TE professionals believe that their students are not college bound and its curriculum is not college preparatory, how can it attempt to change societal perceptionsthat they perceive to be negative?

Based on these data, one may conclude that TE sees itself as a CTE program and not a college preparatory subject. Each of the various employment positions represented in this study shared this perspective. While advances within TE have attempted to move the profession toward becoming a core academic subject partnered with math and science, TE continues to be perceived as career and technical education by its own members and other stakeholders. Despite decades of work on the part of the ITEA leadership and others to fundTE programs 
separately from CTE programs, the respondents to this survey maintained TE is a CTE program and Perkins funding is critical to its survival. Unfortunately, funding allocations often determine what happens to TE programs. Programs can suffer significantly when resources are limited and the competition forthem increases (Akmal et al., 2002).

There are clearly different perspectives about pre-engineering programs in contrast to TE programs. If pre-engineering is such an important part of TE, as some profess, then why does this apparent discrepancy exist? It is unclear why pre-engineering programs, such as EngineeringbyDesign and PLTW ${ }^{\circledR}$ that grew to a large extent out of TE, are not viewed the same as technology education. Have we made progress in positioning TE as “The New Basic?" If engineering programs such as EngineeringbyDesign and PLTW ${ }^{\mathbb{B}}$ are excluded, then the researchers conclude that the respondents believed the answer is "no."

\section{References}

Akmal, T., Oaks, M. M., \& Barker, R. (2002). The status of technology education: A national report on the state of the profession Journal of Industrial Teacher Education, 39(4), Retrieved January 12, 2008, from http://scholar.lib.vt.edu/ejournals/JITE/v39n4/

Benson, M. J. (1993). Positioning and marketing technologyeducation: Joining forces with the establishment. Reston, VA: International Technology Education Association.

Chafy, R. (1997). Exploring the intellectual foundation of technology education: from Condorcet to Dewey. Journal of Technology Education, 9(1), 6-19.

Daugherty M., \& Wicklein, R. (1993). Mathematics, science, and technology teachers' perceptions of technology education. Journal of Technology Education, 4(2), 28-43.

Dillman, D. (2000). Mail and internet surveys: The tailored design method( $2^{\text {nd }}$ edition). New York: John Wiley \& Sons, Inc.

Erekson, T., \& Shumway, S. (2006). Integrating the study of technology into the curriculum: A consulting teacher model.Journal of Technology Education, 18(1), 27-38.

Field, A. (2005). Discovering statistics using SPSS (2 $2^{\text {nd }} e d$.). Thousand Oaks, CA: Sage Publications.

Fink, A., \& Kosecoff, J. B. (2005). How to conduct surveys: A step-by-step guide $\left(3^{\text {rd }}\right.$ ed.). London: Sage Publications.

International Technology Education Association(1996). Rationale and structure for the study of technology, Reston, VA: Author.

International Technology Education Association (2000). Standards for technological literacy: Content for the study of technology Reston, VA.

International Technology Education Association (2002). Addenda to Standards for technological literacy: Content for the study of technology Reston, VA.

International Technology Education Association (2008). Engineering by design: Center to advance the teaching of technology \& science (CATTS).

Retrieved January 12, 2008, from http://www.iteaconnect.org/EbD/CATTS/catts.htm 
Patten, M. L. (2004). Understanding research methods: An overview of the essentials ( $4^{\text {th }}$ edition). Glendale, CA: Pyrczak Publishing.

Pearson, B., \& Young, A. T. (Eds.). (2002). Technically speaking: Why all Americans need to know more about technology. Washington, DC: National Academy Press.

Raizen, S. A., Sellwood, P., Todd, R. D., \& Vickers, M. (1995). Technology education in the classroom: Understanding the designed world San Francisco, CA: Jossey-Bass Publishers.

Rogers, G. (1995). Technology education curricular content: A trade and industrial education perspective. Journal of Industrial Teacher Education, 32(3), 59-74.

Roman, H. T. (2006). The undeniable link between engineering and technology education. Tech Directions, 66(4), 16-19.

Sanders, M. (2001). New paradigm or old wine? The status of technology education practice in the United States.Journal of Technology Education, 12(2), 35-55.

Savage, E., \& Sterry, L. (1990). A conceptual framework for technology education. International Technology Education Association. Reston, VA.

Streichler, J. (1985). AIAA becomes ITEA: A welcome and a perspective.Journal of Epsilon Pi Tau, 11(1\&2), 2-3.

Wicklein, R., \& Hill, R. (1996). Navigating the straits with research or opinion? Setting the course for technology education.International Journal of Technology and Design Education, 6(1), 31-43.

Wicklein, R. C. (2006). Five good reasons for engineering as the focus for technology education. The Technology Teacher, 65(7), 25-29.

Wright, M. D. (2004). Change in technology teacher education? Paper presented at the Mississippi Valley Technology Teacher Education Conference. Rosemont, IL. 